\title{
Endosonographers' approach to delivering a diagnosis of pancreatic cancer: obligated but undertrained
}

Authors

Institution
Srinadh Komanduri, Sarah Quinton, Arth Srivastava, Laurie Keefer

Division of Gastroenterology and Hepatology, Northwestern University Feinberg School of Medicine, Chicago, Illinois, USA submitted 24. July 2015 accepted after revision 12. October 2015

\section{Bibliography}

Dol http://dx.doi.org/

10.1055/s-0041-109085

Published online: 11.1.2016

Endoscopy International Open 2016; 04: E242-E248

(c) Georg Thieme Verlag KG

Stuttgart · New York

E-ISSN 2196-9736

Corresponding author

Srinadh Komanduri, MD, MS

Division of Gastroenterology

and Hepatology

Northwestern University

Feinberg School of Medicine

676 St. Clair Street, 14-003

Chicago, Illinois 60611

USA

Fax: +1-630-908-7499

koman1973@gmail.com
Background and study aims: No data are available on the practice patterns of endosonographers as they pertain to the disclosure of a pancreatic cancer diagnosis. We sought to understand the current practice and coping strategies of physicians who perform endoscopic ultrasound (EUS) procedures in patients with suspected pancreatic cancer.

Methods: This study used a nonexperimental, cross-sectional survey design. A total of 707 endosonographers were contacted and asked to complete an online survey encompassing both demographic and practice data. In addition, participants had the option to complete a second survey assessing common coping strategies.

Results: A total of 152 physicians (22\%) participated in the study. The sample was split between community (47\%) and academic centers (53\%). A total of $92 \%$ of the respondents felt an obligation to share a cancer diagnosis when it was available

\section{Introduction}

\section{$\nabla$}

Pancreatic cancer is the fourth most common cause of cancer-related deaths in the United States $[1,2]$. The prognosis for patients with pancreatic cancer is extremely poor, with the vast majority of them dying within 1 year after receiving this diagnosis $[1,3,4]$. Patients undergo a number of diagnostic procedures to determine the presence of pancreatic cancer, and typically, the primary care physician or oncologist is tasked to deliver the results. However, endoscopic ultrasound-guided fine-needle aspiration (EUS-FNA) has now become the standard of care for sampling pancreatic mass lesions [5], which has increased the likelihood that endosonographers will be the first to make the diagnosis. In addition, with the greater utilization of on-site cytopathology, preli-

\section{License terms}

(이요 $\Theta \circledast$
* The results of this study were presented orally at Digestive Diseases Week, May 2014, Chicago, Illinois, USA. to them; however, only $45 \%$ felt they were adequately trained to do so. Comfort levels were higher in those who performed more than 200 EUS procedures annually and in those practicing for longer than 5 years $(P=0.044)$. A total of 98 physicians (64.5\%) also completed the Brief COPE questionnaire, and the results indicated that the more experienced endosonographers were less likely to experience emotional distress when disclosing a cancer diagnosis.

Conclusion: The comfort level for disclosing a pancreatic cancer diagnosis after EUS appears to be higher in experienced endosonographers ( $>5$ years in practice) and in those who conduct a higher volume of procedures. Although the majority of endosonographers feel obligated to disclose a cancer diagnosis, the lack of time and proper training is limiting. Formal communication skills training within a gastrointestinal fellowship should be considered.

minary FNA results are usually available at the time of the procedure, when patients and their families are still present. Therefore, endosonographers are now often faced with the decision of whether to be the first health care providers to disclose a pancreatic cancer diagnosis.

This paradigm shift in the diagnosis of pancreatic cancer has highlighted a major training gap among interventional gastroenterologists - effective physician communication about cancer and its prognosis. Strong physician communication skills have been linked to higher levels of patient satisfaction, better outcomes, greater adherence to therapies, reduced patient anxiety [6-8], and even increased cancer survival rates $[9,10]$. Furthermore, studies have shown that significant levels of physician stress and burnout are related, among other factors, to inadequate training and uncertainty regarding how to convey difficult news $[11,12]$. 
Effective communication in the setting of oncology has been stratified into three skills: (i) delivery of the diagnosis and proper medical information, (ii) provision of emotional support, and (iii) discussion and support of palliative care [13]. Although the third component may be less relevant for endosonographers, being prepared to disclose a pancreatic cancer diagnosis and to support the patient emotionally is a realistic expectation. The requirement for such skills poses a difficult clinical challenge for gastroenterologists who have not been adequately trained to address these issues with patients and/or cope with their own emotional reactions in this role.

Oncologists communicate a new cancer diagnosis on average 35 times per month, essentially on a daily basis [14]. Therefore, communication skills training is a formal component of hematology/ oncology fellowship training, incorporating cognitive, affective, and behavioral components with the goal of promoting greater self-awareness [15]. Communication skills must be acquired during both clinical experience and formalized training [15]. Formal communication skills training is a part of most medical school curricula through didactics and small-group role playing but is not required during medical residencies or fellowships. The recently updated 2014 Accreditation Council for Graduate Medical Education (ACGME) guidelines (http://www.acgme.org/acgmeweb/Portals/0/PDFs/Milestones/InternalMedicineMilestones. pdf) now emphasize the importance of training internal medicine residents in communication skills, but not specifically in disclosing diagnoses. Furthermore, communication skills training is not currently a requirement for gastroenterology training, despite the increasing need to discuss new cancer diagnoses with our patients. Whether the responsibility to disclose a diagnosis should fall to the endosonographer or the oncologist is unclear. Regardless, it is important that endosonographers who do choose to initiate the cancer discussion exhibit optimal communication skills, both for their patients' and for their own personal wellbeing.

Extensive literature is available on the efficacy of EUS for the diagnosis and staging of pancreatic cancer, but no data are available on how best to communicate this information to the patient or family. Furthermore, although coping styles among gastroenterologists have been studied [16], no studies to date have specifically focused on how endosonographers cope with the increasing demand of being the first health care providers to convey the diagnosis of pancreatic cancer to a patient.

The aim of this study was to elucidate the current practice patterns, comfort levels, and coping styles of academic and community endosonographers in the context of disclosing a pancreatic cancer diagnosis. We hypothesized that given the lack of formalized training, most endosonographers would hold reservations about disclosing a pancreatic cancer diagnosis after an EUS examination, and that the highest levels of discomfort around disclosure might be influenced by clinical experience and coping style.

\section{Methods}

$\nabla$

\section{Survey design}

This study used a prospective, cross-sectional survey design. Via e-mail, we solicited 707 American Society of Gastrointestinal Endoscopy (ASGE) members from an existing U.S. database of endosonographers to participate. The study was approved by the institutional review board at Northwestern University. The database represents nearly all academic institutions performing
EUS and also a large number of community-based endosonographers. Participants completed an online survey ( $\bullet$ Fig. 1 ) anonymously that included questions about basic demographics, practice data, and factors that might influence the decision to disclose a diagnosis of pancreatic cancer, including coping style.

\section{Demographic and practice data}

Participants were asked to provide information regarding their gender, primary practice setting, years out of training, 4th-year advanced endoscopy training, and number of EUS procedures performed annually, and about the availability of an on-site cytopathologist.

\section{Disclosure of diagnosis}

The second tier of questions assessed the endosonographers' approach to and comfort level around delivering a diagnosis of gastrointestinal cancer. Respondents were asked to rate the following on a 5-point Likert scale: (i) comfort level when disclosing a pancreatic cancer diagnosis vs. another gastrointestinal malignancy; (ii) preference regarding having another physician (e.g., oncologist) deliver the diagnosis; and (iii) perception of the adequacy of their training and reasons for lack of comfort in delivering a cancer diagnosis. Participants were then asked to provide information on the manner in which they disclosed a diagnosis of pancreatic cancer and the amount of time they spent discussing prognosis, available support services, and treatment options. Finally, the respondents were asked if the disclosure of a pancreatic cancer diagnosis was an obligation of the endosonographer and whether they would participate in communication skills training if it were offered to them. Although the respondents were queried about the availability of on-site cytopathology and their comfort with discussing a preliminary diagnosis, the current survey was not designed to compare comfort levels at the disclosure of a preliminary diagnosis with those at the delivery of a final diagnosis.

\section{Physician coping styles}

We subsequently invited the physicians participating in the study to complete a second series of questions assessing their coping mechanisms while disclosing a pancreatic cancer diagnosis. We administered the Brief COPE [17], a 28-item, validated self-report measure examining the frequency of use of common coping strategies. The instructions were adjusted to inquire about coping in the context of "giving difficult or bad news to patients." Response options (on a 4-point Likert scale) ranged from "I haven't been doing this at all" to "I've been doing this a lot." A total of 14 unique coping strategies were identified falling into two subcategories-emotion-focused and problem-focused coping. Coping strategies were considered "regularly used" when a score of 3 or higher was met. Composite scores for emotion-focused coping and problem-focused coping were calculated by summing the scores for the various items that corresponded to the coping style.

\section{Data analysis}

Data were collected through Adobe FormsCentral survey software (Adobe Systems, San Jose, California, USA) and transferred to IBM SPSS Statistics20 (IBM, Armonk, New York, USA) for analysis. Descriptive data were reported as means, frequencies, and percentages. Independent sample $t$ tests and chi-squared tests were used for between-group comparisons. 
Over the past 10 years, there has been a significant paradigm shift in pancreatic cancer diagnosis and staging toward the utilization of endoscopic ultrasound (EUS). This has led many surgeons and oncologists to delay the "cancer discussion" with their patients until this test is performed. As a result, endosonographers are faced with the situation of discussing a new cancer diagnosis with patients.

Proper communication skills training to give a cancer diagnosis has been shown to be very effective in oncology. However, there are no data as such for gastroenterology. While there is extensive literature on the technical merits of EUS, there are no data to demonstrate that endosonographers are adequately trained to "break the bad news." To this end, we would love for you to help us further understand this issue. The following is a short survey we are using to understand the practice of community and academic endosonographers in this regard.

First, we would like to know more about you and your practice:

Gender?

Male

Female

What is your primary practice setting?

Academic medical center

Private practice

Other

What year did you complete training?

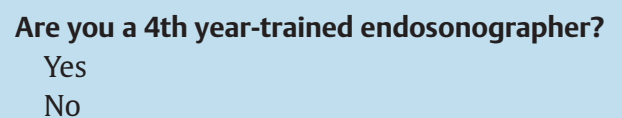

How many EUS examinations do you perform annually?

$50-100$

$100-200$

$200-400$

$>400$

Do you have on-site cytology available?

Yes

No

Who performs your on-site evaluation?

Cytopathologist

General pathologist

Cytotechnologist

Cytotechnologist or fellow with confirmation by the

cytopathologist prior to termination

Is an "adequate" on-site assessment enough information for you

to discuss the diagnosis with the patient and family?

Yes

No

What percentage of the time are you the first person to deliver

the diagnosis to a patient with pancreatic cancer?

Less than $25 \%$

$50 \%$ of the time

$75 \%$ of the time

Almost always (100\%)

If less than $\mathbf{5 0 \%}$ of the time, to whom do you refer the patient for this information most often?

Primary care physician

Oncologist

Surgeon

Referring gastroenterologist
Next, we want to get a better understanding of the factors that influence your decision to disclose or not disclose a diagnosis or provisional diagnosis of pancreatic cancer to a patient.

Practice pattern aside, how comfortable do you feel personally disclosing a cancer diagnosis to your patient?

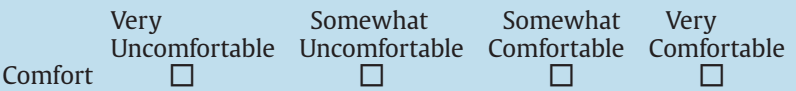

Does your comfort in discussing a cancer diagnosis relate to the type of cancer being discussed (e.g., pancreatic cancer vs. colon cancer)?

Yes

No

Please select all of the following reasons you are uncomfortable providing a pancreatic cancer diagnosis:

Don't feel adequately trained to do this

Anticipate an unpleasant reaction by patient or family

Worry the family will feel too attached to me

Pancreatic cancer is a death sentence

Confusion about how much information should be conveyed

Lack of time to deliver the news or discuss options

I am a technician, and the onus is on the referring physician

Other

How adequate do you feel your training for "delivering bad news," such as a pancreatic cancer diagnosis, has been?

$\begin{array}{lccc}\text { Very } & \text { Somewhat } & \text { Somewhat } & \text { Very } \\ \text { Uncomfortable } & \text { Uncomfortable } & \text { Comfortable } & \text { Comfortable } \\ \square & \square & \square & \square\end{array}$

Where in your training do you think learning communication skills for delivering bad news, such as a pancreatic cancer diagnosis, would be the most useful?

Medical school Residency

Fellowship

Advanced endoscopy fellowship

As an attending faculty member (e.g., CME)

How likely are you to participate in training on how to communicate a new diagnosis of pancreatic cancer to patients?

Very Unlikely Neutral Likely Very Likely
Unlikely

Participate in training 


\section{On average, how much time do you allocate for the delivery of a cancer diagnosis to your patient? \\ $<10$ minutes \\ $10-20$ minutes \\ 20 - 30 minutes \\ $>30$ minutes}

When disclosing a diagnosis of cancer, what percentage of the time do you

Discuss treatment options?

Discuss prognosis?

Answer questions about why this happened?
Provide information on support groups or advocacy organizations?

Provide informationin the form of handouts?

Do you feel endosonographers have an obligation to provide a cancer diagnosis to patients when the information is available to them?

Yes

No

\section{You have completed Part I of this survey!}

Part II examines the ways in which you cope with having to deliver difficult medical news and is completely optional. If you wish to continue, please select Yes and then click Next. If you do not wish to complete Part II, please select No and then click Submit. Yes

No

\section{BRIEF COPE}

These items deal with ways you've been coping with the stress of giving difficult or bad news to patients. There are many ways to try to deal with problems. These items ask what you've been doing to cope with this one. Obviously, different people deal with things in different ways, but I'm interested in how you've tried to deal with it. Each item says something about a particular way of coping. I want to know to what extent you've been doing what the item says. How much or how frequently. Don't answer on the basis of whether it seems to be working or not-just whether or not you're doing it. Use the listed response choices. Try to rate each item separately in your mind from the others. Make your answers as true FOR YOU as you can.

\section{1-I haven't been doing this at all.}

2 - I've been doing this a little bit.

3 - I've been doing this a medium amount.

4-I've been doing this a lot.

1. I've been turning to work or other activities to take my mind off things

2. I've been concentrating my efforts on doing something about the situation I'm in

3. I've been saying to myself "this isn't real"

4. I've been using alcohol or other drugs to make myself feel better.

5. I've been getting emotional support from others.

6. I've been giving up trying to deal with it.

7. I've been taking action to try to make the situation better.

8. I've been refusing to believe that it has happened.

9. I've been saying things to let my unpleasant feelings escape.

10. I've been getting help and advice from other people.

11. I've been using alcohol or other drugs to help me get through it.

12. I've been trying to see it in a different light, to make it seem more positive.

13. I've been criticizing myself.

14. I've been trying to come up with a strategy about what to do.
15. I've been getting comfort and understanding from someone.

16. I've been giving up the attempt to cope.

17. I've been looking for something good what is happening.

18. I've been making jokes about it.

19. I've been doing something to think about it less, such as going to movies, watching TV, reading, daydreaming, sleeping, or shopping.

20. I've been accepting the reality of the fact that it has happened

21. I've been expressing my negative feelings.

22 . I've been trying to find comfort in my religion or spiritual beliefs.

23. I've been trying to get advice or help from other people about what to do.

24. I've been learning to live with it.

25. I've been thinking hard about what steps to take.

26. I've been blaming myself for things that happened.

27. I've been praying or meditating.

28. I've been making fun of the situation.

Part II Complete! This concludes our survey. Thank you for your time!

Fig. 1 Continuation. 


\section{Results}

$\nabla$

\section{Study sample}

For this survey, we contacted 707 ASGE members in an existing national database of endosonographers, 162 of whom participated. The 10 physicians who initiated the survey but did not complete it were excluded from the final analysis, resulting in a total sample size of 152 (22\% response rate).

The physician demographic and practice data are summarized in - Table 1. The majority of our respondents were male (86.2\%). Of those surveyed, $62 \%$ had completed advanced fellowship training in EUS, with a mean of $10.6 \pm 8.5$ years in practice $(62 \%>5$ years and $38 \%<5$ years). The sample was split equally between community (47\%) and academic (53\%) endosonographers. Finally, $69 \%$ of the respondents performed more than 200 EUS procedures annually, and $90 \%$ had on-site cytology available to them.

\section{Disclosure of a pancreatic cancer diagnosis}

Nearly all (92\%) respondents felt an obligation to share a cancer diagnosis when it was available to them; however, only $55 \%$ felt that an "adequate" on-site assessment was sufficient for them to do so. Nonetheless, only $13 \%$ of those surveyed actually referred the patient to another physician for disclosure of the diagnosis. Comfort levels were significantly higher in those who performed more than 400 EUS procedures annually $(P<0.05)$; performing 200 EUS procedures annually was sufficient among endosonographers in academic settings ( $75 \%$ vs. $63 \%, P=0.044$; Table 2 ) and among endosonographers who had been in practice for longer than 5 years $(P=0.044)$. No other factors related to disclosure differed significantly by practice type (academic or community) or by years in practice ( $<5$ or $>5$ ), including the availability of on-site cytopathology ( $\bullet$ Table 2 ).

While most of the endosonographers felt obliged to provide the diagnosis of pancreatic cancer, the majority (80\%) surveyed did not discuss the prognosis or offer information on patient or family support, citing lack of time as the most common reason. Most respondents (85\%) spent less than 20 minutes disclosing a new pancreatic cancer diagnosis, with $25 \%$ allotting 10 minutes or less. The most common reasons endosonographers felt uncomfortable disclosing a diagnosis were the following: (i) lack of adequate time to discuss (46\%); anticipation of an unpleasant reaction from the patient or family (33\%); the idea that pancreatic cancer is a death sentence (27\%); confusion regarding how much information to disclose (22\%); and lack of adequate training (16\%) ( Table 3). Although the majority of endosonographers felt obligated to disclose a diagnosis, only $45 \%$ felt they were adequately trained to do so.

\section{Communication skills training}

None of the endosonographers surveyed had formal communication skills training during their residency or fellowship. When questioned as to the optimal time for this training, 92 (61\%) felt that this should be offered during residency or fellowship training to provide the greatest impact. Despite the lack of comfort with current training, only $15 \%$ of all the endosonographers surveyed were willing to participate in communication skills training if it were offered to them now.

\section{Physician coping}

Of the 152 physicians participating in the first survey, 98 (64.5\%) agreed to complete the Brief COPE questionnaire. The sample was split between community (43\%) and academic medical settings
Table 1 Baseline characteristics of endosonographers participating in a study of their approaches to delivering a diagnosis of pancreatic cancer $(\mathrm{N}=$ 152).

\begin{tabular}{|l|c|}
\hline Characteristic & Value \\
\hline Demographics & $131(86.2)$ \\
\hline Male, $\mathrm{n}(\%)$ & $94(61.8)$ \\
\hline 4th-year training, $\mathrm{n}(\%)$ & $10.6(8.5)$ \\
\hline Years since completion of training, mean (SD) & \\
\hline Practice setting, $\mathrm{n}(\%)$ & $80(53)$ \\
\hline Academic & $72(47)$ \\
\hline Private practice & $10(7)$ \\
\hline Annual volume of EUS procedures, $\mathrm{n}(\%)$ & $36(24)$ \\
\hline $50-100$ & $64(42)$ \\
\hline $100-200$ & $42(27)$ \\
\hline $200-400$ & $137(90)$ \\
\hline$>400$ & \\
\hline On-site assessment available, $\mathrm{n}(\%)$ & \\
\hline
\end{tabular}

SD, standard deviation; EUS, endoscopic ultrasound.

Table 2 Comparison of endosonographers in academic and private practice with respect to comfort level in disclosing a pancreatic cancer diagnosis.

\begin{tabular}{|llll|}
\hline & Community & Academic & P value \\
\hline Respondents, \% & 47 & 53 & 0.19 \\
\hline$>$ 200 EUS procedures per year, \% & 63 & 75 & 0.044 \\
\hline $\begin{array}{l}\text { 4th-year training, \% } \\
\text { Availability of on-site }\end{array}$ & 26 & 36 & 0.19 \\
\hline $\begin{array}{l}\text { cytopathology, \% } \\
\begin{array}{l}\text { Feeling obligated to disclose } \\
\text { diagnosis, \% }\end{array}\end{array}$ & 90 & 90 & 0.54 \\
\hline $\begin{array}{l}\text { Feeling adequately trained to } \\
\text { disclose diagnosis, \% }\end{array}$ & 93 & 92 & 0.74 \\
\hline
\end{tabular}

EUS, endoscopic ultrasound.

Table 3 Reasons offered for discomfort in disclosing a pancreatic cancer diagnosis $(\mathrm{N}=98)$.

\begin{tabular}{|lc|}
\hline Reason $^{*}$ & $\mathbf{n}(\%)$ \\
\hline Lack of time to deliver or discuss news & $45(46)$ \\
\hline Anticipation of unpleasant reaction & $32(33)$ \\
\hline Thinking that pancreatic cancer is a death sentence & $26(27)$ \\
\hline Confusion about how much information to disclose & $22(22)$ \\
\hline Feeling inadequately trained & $16(16)$ \\
\hline Worry that family will become too attached & $3(3)$ \\
\hline Thinking that I am just a technician & $3(3)$ \\
\hline Other & $13(13)$ \\
\hline
\end{tabular}

(57\%). Of the participants, $86.2 \%$ were male, and among those surveyed, $61.8 \%$ had completed a 4th-year advanced endoscopy fellowship, with a mean of $11.2 \pm 8.5$ years in practice. Of the sample, 69\% had completed more than 200 EUS procedures annually, and $90 \%$ had on-site cytology assessment available. As in the primary survey, the vast majority of the respondents felt an obligation to share a cancer diagnosis when it was available to them; $90 \%$ reported that they felt comfortable or very comfortable in adopting that role, and $83 \%$ endorsed being the first to deliver such news.

Physicians who reported experiencing significant distress around disclosing a diagnosis of cancer cited their concerns as being driven by the anticipation of an unpleasant reaction from the pa- 
Table 4 Coping strategies used by endosonographers when disclosing a pancreatic cancer diagnosis $(\mathrm{N}=98)$.

\begin{tabular}{|l|c|}
\hline Strategy & Percentage, \% \\
\hline Problem-focused coping & \\
\hline Acceptance & 68.4 \\
\hline Positive reframing & 43.9 \\
\hline Seeking social support-emotional & 31.6 \\
\hline Active coping & 30.6 \\
\hline Planning & 24.5 \\
\hline Seeking social support-instrumental & 14.3 \\
\hline Emotion-focused coping & \\
\hline Self-distraction & 30.6 \\
\hline Religion & 20.4 \\
\hline Venting & 18.4 \\
\hline Humor & 14.3 \\
\hline Behavioral disengagement & 4.1 \\
\hline Self-blame & 4.1 \\
\hline Substance use & 2.0 \\
\hline Denial & 2.9 \\
\hline
\end{tabular}

tient (33\%) and/or their personal perception that pancreatic cancer is "a death sentence" (27\%). In the sample, $46 \%$ indicated that their distress was related to not having enough time to speak with the patient regarding diagnosis or treatment, and $22 \%$ indicated that distress was related to confusion over what kind of information to convey.

The respondents used a mixture of emotion-focused and problem-focused coping strategies. The most commonly used coping strategies were the following: acceptance (68\%); positive reframing, or trying to see things in a positive light (44\%); seeking social support-emotional (32\%); active coping, or taking action to circumvent a stressor (31\%); self-distraction (31\%); and religion (20\%). Endosonographers reported using least frequently the strategies of denial, self-blame, and substance abuse ( Table 4). When between-group differences were examined, those in community settings were more likely than those in academic settings to engage in venting $(P=0.02)$. Physicians with fewer than 5 years of experience were more likely to seek instrumental support, such as advice from peers $(P=0.01)$, or to engage in venting $(P=$ 0.02 ) than were more experienced physicians. Perhaps most striking, physicians who anticipated an unpleasant reaction when disclosing a diagnosis were also more like to engage in self-blame $(P=0.001)$. Between-group differences are displayed in Table 5.

\section{Discussion}

\section{$\nabla$}

Physician communication is an important and often overlooked component of patient satisfaction and effective clinical care. Communication skills training is even more essential when a cancer diagnosis is being disclosed. To our knowledge, there are no formal requirements for communication skills training for gastroenterologists. The widespread utilization of EUS for the diagnosis and staging of pancreatic cancer has shifted the expectation of patients for disclosure of diagnosis toward gastroenterologists. We report the results of a survey of U.S. endosonographers with respect to their practices and level of comfort in disclosing a pancreatic cancer diagnosis. Although nearly all endosonographers felt obligated to disclose a new diagnosis of pancreatic cancer after EUS-FNA, very few felt adequately trained to perform this
Table 5 Between-group comparisons of coping strategies among endosonographers $(\mathrm{N}=98)$.

\begin{tabular}{|c|c|c|}
\hline & Chi-squared test & $P$ value \\
\hline \multicolumn{3}{|c|}{$\begin{array}{l}\text { Primary practice setting } \times \text { coping } \\
\text { strategy }\end{array}$} \\
\hline Venting & $x^{2}(2)=8.3$ & 0.016 \\
\hline \multicolumn{3}{|c|}{$\begin{array}{l}>400 \text { EUS procedures performed } \\
\text { annually } \times \text { coping strategy }\end{array}$} \\
\hline Distraction & $x^{2}(1)=3.9$ & 0.05 \\
\hline Venting & $x^{2}(2)=5.9$ & 0.05 \\
\hline \multicolumn{3}{|c|}{ Years in practice $\times$ coping strategy } \\
\hline Instrumental support & $x^{2}(1)=6.2$ & 0.01 \\
\hline Venting & $x^{2}(2)=7.8$ & 0.02 \\
\hline
\end{tabular}

EUS, endoscopic ultrasound.

task effectively. This lack of experience also influenced the respondents' personal coping.

Communication skills training is an effective component of the oncology fellowship. Multiple studies have validated the impact of communication skills training on patient satisfaction $[13,14$, $18-26]$. The majority of structured communication skills training occurs in medical school, where application to patients is generally conducted as simulation or role playing. Although the ACGME has started to recognize the importance of communication skills for resident physicians, formal requirements are still not in place. The focus of training in gastroenterology has been on mastering medical knowledge and procedural skill sets so that physicians will function successfully in practice (e.g., endoscopy), and very little emphasis is placed on the comprehensive biopsychosocial model, which can significantly reduce patient anxiety, improve clinical outcomes, and empower the provider $[9,26]$.

To date, no studies have assessed communication skills or communication skills training in gastroenterology. This has become even more apparent with the emergence of EUS as a final diagnostic modality for patients suspected to have pancreatic malignancy. Our study highlights the importance and expectations of endosonographers in the disclosure of a pancreatic cancer diagnosis. However, the importance of communication skills training can be extrapolated to all gastroenterologists who face difficult discussions with patients who have colon cancer, irritable bowel syndrome, or inflammatory bowel disease.

One of the challenges of disclosing a diagnosis when EUS-FNA is performed is the availability of a final diagnosis. The role of the on-site cytopathologist is to assess specimen adequacy, not to provide an on-site diagnosis per se. However, in practice, we know from experience that an "adequate" on-site assessment is generally always predictive of a diagnosis of malignancy. In theory, if the endosonographer is to disclose the diagnosis, he or she should wait until a final diagnosis is issued. This situation remains unclear as only $53 \%$ of the endosonographers surveyed felt comfortable in disclosing a diagnosis based solely on on-site assessment, which may be indicative of avoidance and discomfort in breaking the news.

In addition, understanding how physicians cope with conveying difficult news, particularly a diagnosis with such high mortality rates, is important and often neglected. The current study also highlights that those surveyed were likely to use a variety of problem-focused and emotion-focused coping strategies when detecting and delivering the diagnosis of pancreatic cancer. Previous studies have shown that problem-focused strategies, such 
as active coping, planning, seeking out emotional and instrumental support, acceptance, and positive reframing, are associated with a decrease in psychological distress. In our study, the physicians with more experience and those with a high volume of patients appeared to use these adaptive strategies more frequently, indicating they were less likely than less experienced physicians to suffer psychological distress as a result of their work. Less experienced physicians, and those with a lower volume of cases, were less likely to use problem-focused strategies and more likely to engage in less productive strategies, such as distraction and venting. It is possible that as physicians become more experienced, they become better able to cope with the complexity of the situation. Furthermore, more recently trained physicians who have focused primarily on procedural training may be more prone to the negative impacts of stress. Those who anticipated a bad reaction from a patient or felt that they did not have enough time to speak with a patient engaged in the least helpful coping strategies, and these concerns may be alleviated with training or simulation experiences. Indeed, the majority of respondents indicated that training would be most impactful during residency and fellowship.

The current survey study highlights the lack of communication skills training in physicians currently providing a new pancreatic cancer diagnosis after EUS-FNA. There appears to be some increase in comfort with a high volume of cases and longer years of experience. Although there may be technical differences between academic and community endosonographers, it appears that both groups are equally uncomfortable with their ability to disclose a new diagnosis of pancreatic cancer.

This study has some limitations. There are inherent biases introduced with surveys and from the utilization of a set database of endosonographers. The $22 \%$ response rate is good for a survey study but may still not be truly representative of all physicians performing EUS, particularly those who are most uncomfortable about the topic. Secondly, analysis of disclosure based on preliminary specimen adequacy vs. final diagnosis was not assessed and could be affected by the rigidity of cytopathology disclosure of the diagnosis on site. In addition, it is possible that endosonographers would not disclose a diagnosis until completion of the staging work-up so as to better assess disease prognosis. Finally, the current study was limited to U.S. endosonographers and does not represent the global endosonography community. The strength of this study includes the overall response rate and a balanced participation from academic, community, experienced, and novice endosonographers.

In summary, comfort levels in disclosing a pancreatic cancer diagnosis after performing EUS appear to be higher for endosonographers with a greater volume of cases and more experience but are not influenced by practice setting. Furthermore, experienced endosonographers used more effective coping strategies; however, with practice patterns rapidly shifting toward endosonographers being the first to disclose a diagnosis, experience may not be enough to reduce provider distress. While the majority of endosonographers feel obligated to disclose a pancreatic cancer diagnosis after EUS, the lack of time and proper training, particularly among more junior providers, limits their comfort with disclosure and results in negative coping styles. Formal communication skills training within gastroenterology fellowships should be considered.

\section{References}

1 Hariharan D, Saied A, Kocher HM. Analysis of mortality rates for pancreatic cancer across the world. HPB (Oxford) 2008; 10: 58-62

2 Coughlin SS, Calle EE, Patel AV et al. Predictors of pancreatic cancer mortality among a large cohort of United States adults. Cancer Causes Control 2000; 11: 915 - 933

3 Satoru Kawakami SA, Murai YC, Arai GA et al. Physician's attitudes towards disclosure of cancer diagnosis to elderly patients: a report from Tokyo, Japan. Arch Gerontol Geriatrics 2001; 33: 29-36

4 Takhar AS, Palaniappan P, Dhingsa R et al. Recent developments in diagnosis of pancreatic cancer. Br Med J 2004; 329: 668 -673

5 Singy P, Bourquin C, Sulstarova B et al. The impact of communication skills training in oncology: a linguistic analysis. J Cancer Educ 2012; 27: $404-408$

6 Kissane DW, Bylund CL, Banerjee SC et al. Communication skills training for oncology professionals. J Clin Oncol 2012; 30: 1242 - 1247

7 Epstein RM, Hadee T, Carroll J et al. "Could this be something serious?" Reassurance, uncertainty, and empathy in response to patients' expressions of worry. J Gen Intern Med 2007; 22: 1731-1739

8 Hack T. Psycho-oncology special issue on communication. Psychooncology 2005; 14: 797-798

9 Butow PN, Coates AS, Dunn SM. Psychosocial predictors of survival in metastatic melanoma. J Clin Oncol 1999; 17: 2256-2263

10 Lobb EA, Butow PN, Kenny DT et al. Communicating prognosis in early breast cancer: do women understand the language used? Med J Aust 1999; 171: $290-294$

11 Azu MC, Jean S, Piotrowski JM et al. Effective methods for disclosing breast cancer diagnosis. Am J Surg 2007; 194: 488-490

12 Holland JC. History of psycho-oncology: overcoming attitudinal and conceptual barries. Psychosom Med 2002; 64: 206 - 221

13 Goelz T, Wuensch A, Stubenrauch $S$ et al. Specific training program improves oncologists' palliative care communication skills in a randomized controlled trial. J Clin Oncol 2011; 29: 3402-3407

14 Baile WF. Training oncology practitioners in communication skills. J Pediatr Hematol Oncol 2011; 33: 02115-S122

15 Moore PM, Rivera Mercado S, Grez Artigues M et al. Communication skills training for healthcare professionals working with people who have cancer. Cochrane Database Syst Rev 2013; 3: CD003751

16 Keswani RN, Taft TH, Cote GA et al. Increased levels of stress and burnout are related to decreased physician experience and to interventional gastroenterology career choice: findings from a US survey of endoscopists. Am J Gastroenterol 2011; 106: 1734 - 1740

17 Carver CS. You want to measure coping but your protocol's too long: consider the brief COPE. Int J Behav Med 1997; 4: 92-100

18 Fallowfield L, Lipkin M, Hall A. Teaching senior oncologists communication skills: results from phase I of a comprehensive longitudinal program in the United Kingdom. J Clin Oncol 1998; 16: 1961-1968

19 Alelwani SM, Ahmed YA. Medical training for communication of bad news: a literature review. J Educ Health Promot 2014; 3: 51

20 Barnes S, Gardiner C, Gott M et al. Enhancing patient-professional communication about end-of-life issues in life-limiting conditions: a critical review of the literature. J Pain Symptom Manage 2012; 44: 866 879

21 Buss MK, Lessen DS, Sullivan AM et al. Hematology/oncology fellows' training in palliative care: results of a national survey. Cancer 2011; 117: 4304-4011

22 De Vries AM, de Roten Y, Meystre C et al. Clinician characteristics, communication, and patient outcome in oncology: a systematic review. Psychooncology 2014; 23: $375-381$

23 Fujimori M, Shirai $Y$, Asai $M$ et al. Effect of communication skills training program for oncologists based on patient preferences for communication when receiving bad news: a randomized controlled trial. J Clin Oncol 2014: 32: 2166-2172

24 Tulsky JA, Arnold RM, Alexander SC et al. Enhancing communication between oncologists and patients with a computer-based training program: a randomized trial. Ann Intern Med 2011; 155: 593-601

25 Turner M, Payne S, O'Brien T. Mandatory communication skills training for cancer and palliative care staff: does one size fit all? Eur J Oncol Nurs 2011; 15: 398-403

26 Uitterhoeve RJ, Bensing JM, Grol RP et al. The effect of communication skills training on patient outcomes in cancer care: a systematic review of the literature. Eur J Cancer Care (Engl) 2010; 19: 442-457 